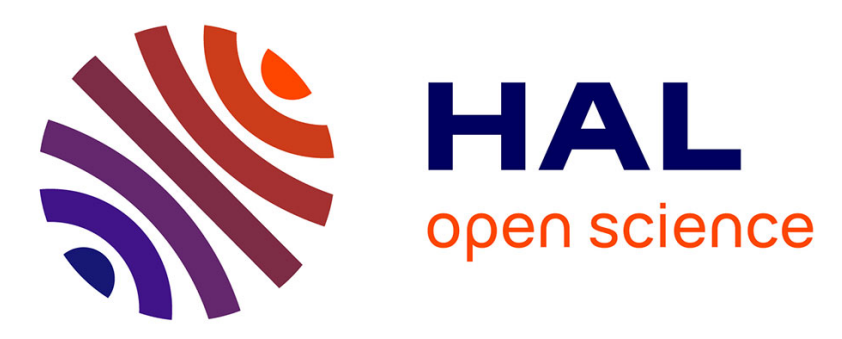

\title{
An Unexpected Subdural Collection: Story of a Prostatic Metastasis
}

Pierre Bourdillon, Caroline Apra, Philippe Cornu, Dorian Chauvet

\section{To cite this version:}

Pierre Bourdillon, Caroline Apra, Philippe Cornu, Dorian Chauvet. An Unexpected Subdural Collection: Story of a Prostatic Metastasis. Clinical Genitourinary Cancer, 2016, 14 (4), pp.e405-e407. 10.1016/j.clgc.2016.01.008 . hal-01991980

\section{HAL Id: hal-01991980 \\ https://hal.sorbonne-universite.fr/hal-01991980}

Submitted on 24 Jan 2019

HAL is a multi-disciplinary open access archive for the deposit and dissemination of scientific research documents, whether they are published or not. The documents may come from teaching and research institutions in France or abroad, or from public or private research centers.
L'archive ouverte pluridisciplinaire HAL, est destinée au dépôt et à la diffusion de documents scientifiques de niveau recherche, publiés ou non, émanant des établissements d'enseignement et de recherche français ou étrangers, des laboratoires publics ou privés. 


\title{
An Unexpected Subdural Collection: Story of a Prostatic Metastasis
}

\author{
Pierre Bourdillon, ${ }^{1,2,3}$ Caroline Apra, ${ }^{1,3}$ Philippe Cornu, ${ }^{1,3}$ Dorian Chauvet ${ }^{1,4}$
}

\section{Clinical Practice Points}

- Subdural metastasis is unusual, but prostate cancer represents 1 of 5 cases.

- Subdural metastasis of prostate cancer usually mimics acute, mixed, subacute, or chronic subdural hematoma.

- In case of subdural collection in a patient with a medical history of prostate cancer, always discuss performing contrast-enhanced head magnetic resonance imaging when there is a bone localization of cancer or atypical features on head computed tomography scan, for instance, a spontaneous hyperdensity hanging from the dura within a biconcave hypodensity.

- When a patient with a medical history of prostate cancer undergoes surgery for a subdural hematoma drainage, consider a burr hole or trephine hole technique rather than a percutaneous procedure such as twist-drill, and always send a sample for histopathologic analysis.

Keywords: Intracranial, Prostate adenocarcinoma, Prostate cancer, Subdural hematoma, Subdural metastasis

\section{Introduction}

Subdural collections are characterized by a biconcave radiologic aspect regardless of what they are made because of the lack of adherence between dura and arachnoid. In most cases, such a collection corresponds to a hematoma or an empyema, ${ }^{1,2}$ and the diagnosis based on clinical and radiologic data usually is straightforward. Nevertheless, other uncommon diagnoses, such as metastasis, may occur. Although dural metastases are well known, with hundreds of cases published, ${ }^{3}$ subdural metastases are extremely rare. The most frequent origin is prostate $(1 / 5$ cases $),{ }^{4}$ and less than 15 observations have been reported. ${ }^{5-15}$ These few cases were misdiagnosed because of clinical and radiologic similarity to subdural hematomas. Patients underwent drainage surgery, which is not an appropriate treatment in this case. The aim of the present study is to find clues to help make the correct diagnosis in such cases, with a review of the literature and a new case.

${ }^{1}$ Department of Neurosurgery, Hôpital de la Pitié-Salpêtrière, Paris, France

${ }^{2}$ University of Lyon, Université Claude Bernard Lyon 1, Lyon, France

${ }^{3}$ Sorbonne University, Université Pierre et Marie Curie Paris 6, Paris, France

${ }^{4}$ Department of Neurosurgery, Fondation Rothschild, Paris, France

Address for correspondence: Pierre Bourdillon, MD, MSc, Department of Neurosurgery, Hôpital de la Pitié-Salpêtrière, 47-83 Boulevard de l'hôpital, 75013 Paris, France E-mail contact: pierre.bourdillon@neurochirurgie.fr

\section{Case Report}

A 76-year-old man developed a left hemiparesis with increasing morning headache over 1 week. His medical history included only a non-evolutive prostate adenocarcinoma under hormone therapy, diagnosed 3 years before, for which the patient went to a routine follow-up to his urologist. Because of the new symptomatology, the urologist referred the patient to the department of radiology for a head computed tomography (CT) scan. Head CT scan without contrast revealed a mixed hypo/hyperintensity in the right subdural space (Figure 1), unsurprisingly interpreted as a subdural chronic/ subacute hematoma. The patient was referred to our neurosurgical unit.

Surgery was performed through a $4-\mathrm{cm}$ trephine hole. Bone and dura had a normal appearance, but the subdural collection was a yellowish fibrous lesion instead of a hematoma with a typical chronic blood appearance. Surgical evacuation was performed as completely as was technically possible. Because of this unusual aspect, a sample was sent for microbiological and histopathologic analysis. Microbiological direct examination was normal, and the patient received steroids and presented a clear neurologic improvement.

Histopathologic analysis diagnosed a prostate adenocarcinoma metastasis with a high expression of prostate-specific antigen. A whole-body CT scan and brain magnetic resonance imaging (MRI) (Figure 2) performed after this result revealed no other metastasis, which was consistent with the urologist's description of non-evolutive prostate cancer. The patient died a few weeks later in the palliative care unit. 
Figure 1 A, Preoperative Head CT Scan Without Contrast Showing a Subdural Isointensity. B, Postoperative Head CT Scan Without Contrast Showing an Hypointensity in Front of the Trephine Hole

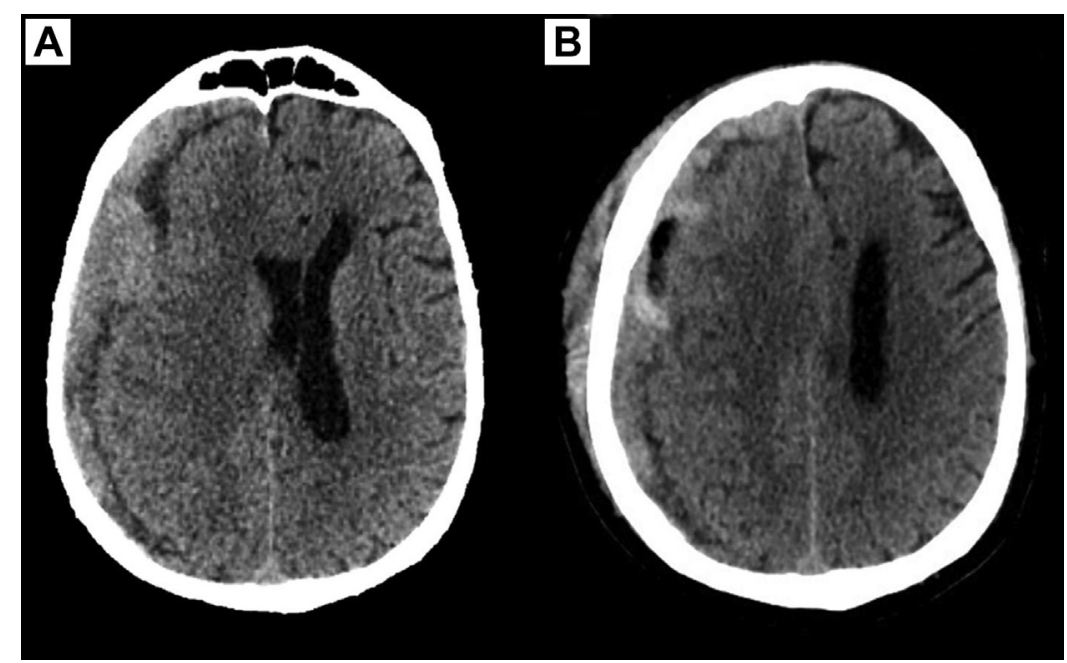

Figure 2 T1 (A), T1 With Gadolinium (B, D), and (C) FLAIR Sequences of the Postoperative Brain MRI. B, Contrast Enhancement of the Subdural Space Involving the Contralateral Dura Suggests a Tumoral Pathology. D, Only Incomplete Removal of the Lesion Is Possible Through the 4-cm Trephine Hole Because of the Fibrous Texture of the Lesion

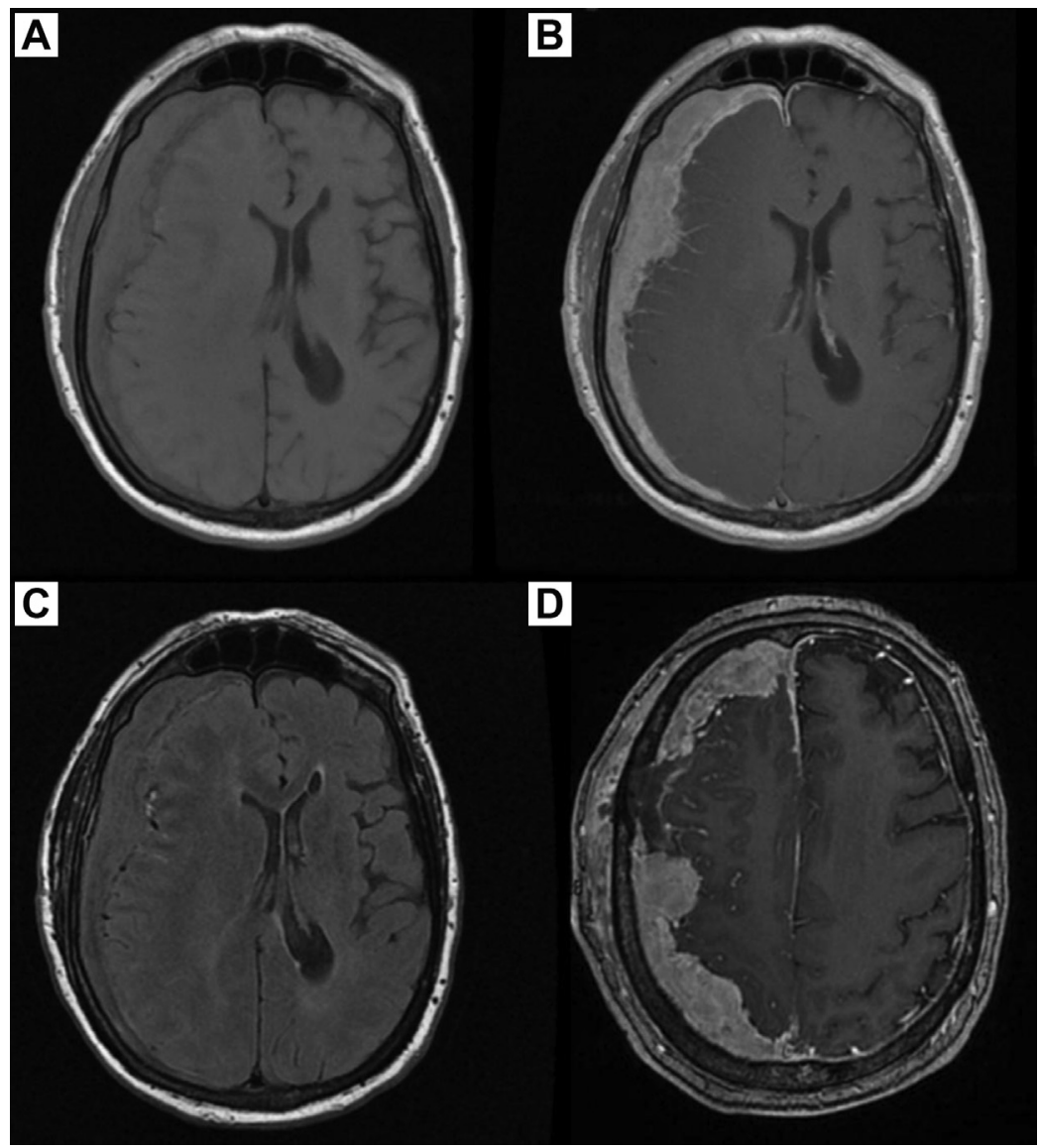




\section{Discussion}

Although subdural metastases are extremely rare, prostate cancer accounts for the majority of them in male patients. ${ }^{3}$ Except in $2(15 \%)$ of the 13 cases (including the present case) reported in the literature, the diagnosis was made during a surgical procedure. In these 2 cases, ${ }^{7,12}$ the patients presented an extensive metastatic spreading of prostate cancer and had benefited from an MRI because of uncommon features on head CT scan. MRI showed an extensive and homogenous dural and subdural enhancement involving the contralateral subdural space, as we found on MRI performed in our patient after surgery (Figure 2).

Subdural metastasis of prostate cancer can mimic a chronic subdural hematoma (30\%), an acute hematoma (23\%), or, more often, a mixed or subacute subdural hematoma. ${ }^{5-15}$ In $38 \%$ of patients, subdural metastasis of prostate cancer is associated with a real subdural chronic hematoma. In such cases, images do not show blood sedimentation as in usual mixed hematoma, but a nonenhanced hyperdensity attached on dura.

In $54 \%$ of the 13 cases reported, the patient showed a bone localization of prostate cancer when subdural metastasis occurred. In all cases but the one reported in this study, the patients had at least a bone localization or an atypical feature on head CT scan.

\section{Conclusions}

Although subdural metastasis is extremely rare compared with subdural hematoma or empyema, this diagnosis should be discussed for patients with a medical history of prostate cancer. The diagnosis is straightforward on MRI because of contrast enhancement, whereas it may be challenging on noncontrast head CT scan. Thus, we propose to consider preoperative MRI for patients with known bone localizations of prostate cancer or atypical features on head CT scan, for instance, a spontaneous hyperdensity hanging from the dura within a biconcave hypodensity. Moreover, when patients undergo subdural drainage, we highly recommend not to use a percutaneous technique but a slightly more extensive one, such as a trephine hole, which allows direct visual control and easy sampling.

\section{Disclosure}

The authors have stated that they have no conflicts of interest.

\section{References}

1. Guenot M. Chronic subdural hematoma: diagnostic imaging studies. Neurochirurgie 2001; 47:473-8.

2. Levy RM. Brain abscess and subdural empyema. Curr Opin Neurol 1994; 7:223-8.

3. Laigle-Donadey F, Taillibert S, Mokhtari K, Hildebrand J, Delattre JY. Dural metastases. J Neurooncol 2005; 75:57-61.

4. Nayak L, Abrey LE, Iwamoto FM. Intracranial dural metastases. Cancer 2009 115:1947-53.

5. Bucci MN, Farhat SM. Metastatic adenocarcinoma of the prostate as a cause of subdural hematoma. J Urol 1986; 135:803-4.

6. Tomlin JM, Alleyne CH. Transdural metastasis from adenocarcinoma of the prostate mimicking subdural hematoma: case report. Surg Neurol 2002; 58:329-31.

7. Dols MC, Calle SG, Chamorro EV, Díaz IA, Pino AM, García JA. Dural metastases with subdural hematoma from prostate cancer. Oncologia 2005; 28:407-11.

8. Cheng YK, Wang TC, Yang JT, Lee MH, Su CH. Dural metastasis from prostatic adenocarcinoma mimicking chronic subdural hematoma. J Clin Neurosci 2009; 16 : 1084-6.

9. Dorsi MJ, Zenonos G, Hsu W, Huang J. Dural prostate adenocarcinoma metastasis with subdural hematoma mimicking the appearance of an epidural hematoma. Clin Neurol Neurosurg 2010; 112:501-4.

10. Patil S, Veron A, Hosseini P, et al. Metastatic prostate cancer mimicking chronic subdural hematoma: a case report and review of the literature. J La State Med Soc 2010; 162:203-5.

11. George KJ, Lau A, Ellis M, Kiehl TR, Fehlings MG. Metastatic coagulopathic subdural hematoma: a dismal prognosis. Surg Neurol Int 2012; 3:60.

12. Yu W, Sitt C, Cheung TC. Dural metastases from prostate cancer mimicking acute sub-dural hematoma. Emerg Radiol 2012; 19:549-52.

13. Meara ACO, Mahasneh T, Wilson P, Ons BI, Alkhawaja D. Dural prostate metastasis resembling a chronic subdural haematoma. J Surg Case Rep 2012 $5: 7$.

14. N’Dri Oka D, Varlet G, Boni N, Broalet E, Boukassa L, Zeze VBA. Métastase durale d'un adénocarcinome sous-dural aigu intracrânien à propos d'une observation. J Neuroradiol 2013; 27:282-4.

15. Nzokou A, Magro E, Guilbert F, Fournier JY, Bojanowski MW. Subdural metastasis of prostate cancer. J Neurol Surg Rep 2015; 76:e123-7. 